\title{
Role of Essential Drug List in Effective Management of Essential Anti- Malarial Drugs in Healthcare System of Pakistan Challenges in Policy Development to Practice
}

\author{
Madeeha Malik $^{1 *}$, Azhar Hussain¹, Shaffiq M1, Mohamed Azmi Ahmad Hassali² and Asrul Akmal Shafie
}

${ }^{1}$ Hamdard Institute of Pharmaceutical Sciences Hamdard University Islamabad Campus 23-East, Fazal-ul-Haq Road Blue Area, Islamabad 44000, Pakistan

${ }^{2}$ Discipline of Social and Administrative Pharmacy, School of Pharmaceutical Sciences, Universiti Sains Malaysia, 11800 Minden, Penang, Malaysia

\begin{abstract}
Background: Essential anti-malarial drugs are often not available in healthcare facilities when patients need them. Objective: The study aimed to assess role of essential drug list in drug management including availability and stock outs of anti-malarial drugs among public and private primary, secondary and tertiary healthcare facilities in two cities of Pakistan; Islamabad (Federal capital) and Rawalpindi (twin city).
\end{abstract}

Methods: A comparative, cross-sectional study was designed to evaluate the availability, stock outs and management of anti-malarial drugs records in fifty public and private primary, secondary and tertiary healthcare facilities in the twin cities, namely Islamabad (Federal capital) and Rawalpindi. Pre-validated tools i.e. WHO facility indicator form and USAID inventory indicator and drug stock outs form were used to collect data. A structured questionnaire was designed for data collection on drug management from the personnel involved in drug management among both public and private primary, secondary and tertiary healthcare facilities. After the data collection, data was coded and analyzed by using SPSS version 16.

Results: Essential drug list was not available in any of the healthcare facility. Chloroquine and sulfadoxine/ pyrimethamine tablets were the most commonly available anti-malarial drugs in most of the public and private tertiary, secondary and primary healthcare facilities. On the other hand chloroquine injections were not available in any of the public or private tertiary, secondary and primary healthcare facility. Major stock-outs of anti-malarial drugs were seen in both healthcare facilities but the situation was more prevalent in the public healthcare facilities.

Conclusion: The results of the present study conclude that drug management follows different methods in both public and private healthcare facilities in the twin cities. Gaps in drug management including procurement, quantification, inventory control and drug stock outs must be addressed to improve the availability of drugs in healthcare system of Pakistan.

Keywords: Drugs; Drug provision; Malaria; Management

\section{Introduction}

Essential medicines are those that satisfy the priority health care needs of the population and offer a cost-effective solution to the problems of drug stock out in healthcare system of developing countries [1]. They should be selected according to the prevalence of disease, affordability of healthcare system/patient, with assured quality and availability in the appropriate dosage forms. World health organization estimates that nearly 2 billion people around the world lack regular access to essential medicines, and more than $50 \%$ of the population living in different countries in Africa, has no access to essential medicines when they need them [1].

Many developing countries have a limited budget allocation to health care system, thus effecting drug procurements. The expenditures for drug purchases through appropriate selection and procurement techniques must be optimized to ensure the availability of essential medicines and essential drugs list at healthcare facilities [2]. Even though most of the countries publish an essential medicines list, but still the availability of medicines at public-healthcare facilities is under question. Prescribers can treat their patients in a more rational way if they have access to an essential drugs list and essential medicines are available without interrupted supply at the healthcare facilities [3].

The unavailability of anti-malarial drugs at healthcare facilities undermines the efforts done for control and rational treatment of malaria. Effective anti malarial drugs, as recommended in the national malaria treatment policy are often not available in reality where patients need them. This practice is quite common in public sector healthcare facilities in many developing countries [4]. Major anti-malarial drug stock outs in public healthcare facilities have been reported by several studies conducted in Uganda and Kenya [5,6]. The reasons of drug stock-outs vary, but often reflect on the weak drug management system. The regular availability of drugs in the public healthcare system is usually disrupted due to poor resource supply system, weak stock management and inadequate allocation of funds [7].

Pakistan has a progressively growing pharmaceutical industry which has a market value of approx. US\$ 1.72 billion (Ministry of Health, 2009). There are over 400 local manufacturing companies accompanied with 30 multinationals. The pharmaceutical market is a brand market and for an individual molecule, dozens of different brands are registered in the country. The public healthcare facilities providing services at provincial and district levels are categorized as: primary level

${ }^{*}$ Corresponding author: Madeeha Malik, B-Pharm (Hons), M-Phil (Pharmacy), $\mathrm{PhD}$, Hamdard Institute of Pharmaceutical Sciences Hamdard University Islamabad Campus 23-East, Fazal-ul-Haq Road Blue Area, Islamabad 44000, Pakistan, Tel: 92-21-36440035-40; E-mail: madeehamalik15@gmail.com

Received February 12, 2014; Accepted March 16, 2014; Published March 23 2014

Citation: Malik M, Hussain A, Shaffiq M, Hassali MAA, Shafie AA (2014) Role of Essential Drug List in Effective Management of Essential Anti-Malarial Drugs in Healthcare System of Pakistan Challenges in Policy Development to Practice. Pharmaceut Reg Affairs 3: 120. doi:10.4172/2167-7689.1000120

Copyright: $\odot 2014$ Malik M, et al. This is an open-access article distributed under the terms of the Creative Commons Attribution License, which permits unrestricted use, distribution, and reproduction in any medium, provided the original author and source are credited. 
health care facilities (basic health units, rural health centers, mother and child health centers, TB clinics and dispensaries), secondary level health care facilities (tehsil headquarter hospitals and district head quarter hospitals) and tertiary level health care facilities (tertiary hospitals, post graduate medical institutes and teaching hospitals). All the tertiary healthcare facilities have a primary healthcare section for treating common diseases including malaria. Cases are referred from lower to higher level depending on severity of problem and available infrastructure.

Public tertiary care health facilities purchase drugs through open tender for their own and their respective secondary and primary healthcare facilities. While in private sector healthcare facilities drugs are usually purchased through restricted tenders, direct negotiations with pharmaceutical companies or wholesalers. The national essential medicines list (NEML) of Pakistan was first drafted in 1994 in consultation with relevant experts. The list was reviewed and updated in 1995, 2000, 2003 and 2007. The current fourth edition of the list (2007) consists of 335 medicines of different pharmacological classes. The health sector in general and public health sector in particular is expected to seriously consider adopting this list. The provincial health departments are responsible for encouraging the hospitals/ institutions for making bulk purchases from within this list [8]. An efficient functioning of pharmaceutical management system should translate in the uninterrupted availability of appropriate quantities of drugs at all times [7]. This is currently not the case in Pakistan, thus rapid assessment of procurement of medicines, inventory control and stock management in healthcare facilities must be performed for better treatment and control of diseases including malaria. The current study is the first ever study to the best of our knowledge which has been designed to assess the role of essential drug list in management of anti-malarial drugs including their availability and stock outs among public and private primary, secondary and tertiary healthcare facilities in two cities of Pakistan; Islamabad (national capital) and Rawalpindi (twin city). The study will provide baseline data, which can serve as a basis for improving the policy development and implementation to enhance drug management performance in maintaining a constant uninterrupted supply of antimalarial drugs in the healthcare system of Pakistan.

\section{Methodology}

\section{Study design}

A comparative, cross-sectional study was designed to evaluate the availability, stock outs (the number of days, a drug was not present in the facility over a recent 12-month period) and management of antimalarial drugs in public and private tertiary, secondary and primary healthcare facilities in the two cities, namely Islamabad (federal capital) and Rawalpindi (twin city). The drugs records included manual ledger, stock record cards, tally sheets or computerized data present at the hospital pharmacies and dispensaries of the healthcare facilities. The study was approved by the Malaria Control Program, Ministry of Health, Government of Pakistan. Written permission for survey was obtained from relevant district health officers (DHO).

\section{Study tools}

Pre-validated tools i.e. world health organization (WHO) facility indicator form and United States agency for international development (USAID) inventory indicator and drugs stock out form were used to collect data regarding availability of anti-malarial drugs on essential drug list of Pakistan and stock outs of anti-malarial drugs $[9,10]$. A structured questionnaire with coded responses was used to get information regarding drug management in the healthcare facilities. The questionnaire was developed through inputs from primary literature, USAID manual and drug supply system. Two focus group discussions were carried out at different time intervals with four different groups including hospital pharmacists, hospital managers, doctors and academia. Each group comprised of three to four participants for the development, finalization, face and content validity of the tool. This method was chosen over the other methods because a number of aspects to be addressed were already identified from the literature and experience of the research team and it was ensured that the key steps involved in drug management in healthcare facilities were covered with all the respondent groups. The questionnaire included four sections. Section I included questions regarding processes of procurement, availability of drug and therapeutic committee (DTC) (This committee evaluates the clinical use of drugs, develops policies for managing drug use, administration, manages the formulary system and determines which drugs will be available and at what cost), in charge of committee (most likely the pharmacist) and type of procurement method. Section II included questions regarding quantification, responsible person for quantification, method used, associated problems with quantification, distribution, storage, type of supply system, disposal of expired drugs, appropriate storage of drugs. Section III included questions regarding inventory control, availability of written procedures, type(s) of inventory records, method of product circulation, timing of stock taking and access to drug information resources. Section IV consisted questions regarding human resources, availability of adequate and appropriate staff, key problems for human resource development and major training needs $[8,10]$.

While the inventory indicator and drugs stock out form included core indicators and some additional indices such as availability of antimalarial drugs (indicated in national essential medicine list of Pakistan), antimalarial drug stock outs and average $\%$ of days out of stock of antimalarial drugs.

\section{Sampling of facilities and respondents}

Based on previous studies and methodologies extrapolated from WHO Expanded Program on Immunization and International Network for Rational Use of Drugs, the sample size for comparative study includes a minimum of ten healthcare facilities in each group [11]. The healthcare facilities were divided into two main groups' i.e. public and private healthcare facilities. A list of all the public and private hospitals for primary care, secondary care and tertiary care in Islamabad and Rawalpindi was obtained from the respective District Health Offices. Simple random sampling technique was used to draw the sample of healthcare facilities from the list by using lottery method. All the ten public as well as private tertiary healthcare hospitals were included in the study. While ten basic health units and ten private GPs clinics were selected randomly from the list for primary healthcare level. On the other hand, as Rawalpindi is the main district having seven tehsils (tehsil is an administrative sub-division of any district in a country) in it. Only five tehsils have a public secondary care hospital (District health quarter hospital). All the five public district health quarter hospitals and one respective private secondary care hospital were included in the study. Thus a total of fifty healthcare facilities situated in the two cities were included in the study.

\section{Data collection and analysis}

Data was collected by the principal investigator along with two teams comprised of five trained data collectors in each team trained by the group of experts including principal investigator [12]. The data collectors were students of the final year Doctor of Pharmacy program. 
Citation: Malik M, Hussain A, Shaffiq M, Hassali MAA, Shafie AA (2014) Role of Essential Drug List in Effective Management of Essential Anti-Malarial Drugs in Healthcare System of Pakistan Challenges in Policy Development to Practice. Pharmaceut Reg Affairs 3: 120. doi:10.4172/21677689.1000120

Page 3 of 7

Antimalarial drugs on national essential medicine list of Pakistan were used for assessment of their availability and stock outs in the tertiary, secondary and primary healthcare facilities for the last one fiscal year i.e. from June 2010 to June 2011. A total of five antimalarial drugs i.e. chloroquine phosphate, sulfadoxine/pyrimethamine, amodiaquine, quinine and artemether/lumefantrine available in different dosage forms were checked. For reviewing the drug availability and stock outs in each facility, information was gathered from tally/bin/stock cards, manual ledgers and computers in some instances. Where none of the above was available, store receipt vouchers, drug revolving fund requisition forms, receipts of purchase or monthly returns records were used. Physical inventory check was also performed for all the drugs to confirm the validity of the records. Data regarding different process of drug management including procurement, quantification, distribution, storage and inventory control was collected with the help of questionnaires filled by in charge of hospital pharmacies and dispensaries including pharmacists where available. After the data collection, data were coded and analyzed using statistical software SPSS version 16.

\section{Results}

Procurement and quantification of drugs in public and private primary, secondary and tertiary healthcare facilities in the two cities

The Drug and Therapeutic Committee was in place in all the public and private tertiary healthcare facilities and was responsible for procurement of drugs for their respective secondary and primary healthcare facilities. A pharmacist was available in all the public and private tertiary and public secondary healthcare facilities and was part of procurement committee but did not play an active role in drug selection and procurement. However, pharmacist was not available in public and private primary and secondary hospitals. Essential drugs list was not available in any of the public or private primary, secondary and tertiary healthcare facility and procurement of drugs was performed through hospital formulary. A detail description of procurement and quantification in public and private primary, secondary and tertiary healthcare facilities in the two cities is given in Table 1.

Drug supply and management in public and private primary, secondary and tertiary healthcare facilities in the twin cities

The type of supply system for drugs was push system in public primary, secondary and tertiary healthcare facilities while no specific supply system was used in private primary, secondary and tertiary healthcare facilities. The storage of drug was comparatively more appropriate in the private tertiary healthcare facilities. Both first expired first out (FEFO) and first in first out (FIFO) methods were being used for drug circulation. Computerized system was only available in few of the private tertiary healthcare facilities for inventory management. Major need for training in inventory management, drug management and computer applications was identified in all the public primary, secondary and tertiary healthcare facilities. A detail description of distribution, storage and inventory management of drugs in public and private primary, secondary and tertiary healthcare facilities in the two cities is given in Table 2 .

Anti-malarial drugs on hospital formulary of different public and private primary, secondary and tertiary healthcare facilities in the twin cities

Chloroquine phosphate and sulphadoxine/pyremethamine tablets were present on hospital formulary of most of the public and private tertiary, secondary and primary healthcare facilities in the twin cities. On the other hand chloroquine injections, syrups, quinine and amidaquine tablets were not part of hospital formulary of most of the public and private tertiary, secondary and primary healthcare facilities although present on EDL of Pakistan. A detail description of antimalarial drugs on hospital formulary of different public and private tertiary, secondary and primary healthcare facilities in the twin cities is given in Table 3 .

\begin{tabular}{|c|c|c|c|c|c|c|}
\hline \multirow{2}{*}{ Indicator } & \multicolumn{2}{|c|}{ Tertiary } & \multicolumn{2}{|c|}{ Secondary } & \multicolumn{2}{|c|}{ Primary } \\
\hline & Public & Private & Public & Private & Public & Private \\
\hline \multicolumn{7}{|l|}{ Procurement } \\
\hline Availability of pharmacist & Yes & Yes & Yes & No & No & No \\
\hline $\begin{array}{l}\text { Procurement } \\
\text { Committee in place }\end{array}$ & Yes & Yes & No & No & No & No \\
\hline $\begin{array}{l}\text { In charge of Procurement } \\
\text { Committee }\end{array}$ & Doctor & Doctor & N.S & N.S & N.S & N.S \\
\hline $\begin{array}{l}\text { Pharmacist part of } \\
\text { Procurement Committee }\end{array}$ & Yes & Yes & No & No & No & No \\
\hline $\begin{array}{l}\text { Written procurement } \\
\text { plan }\end{array}$ & Yes & Yes & $\begin{array}{l}\text { Demand sent to tertiary } \\
\text { care hospital }\end{array}$ & Yes & No & No \\
\hline $\begin{array}{l}\text { Ability to purchase } \\
\text { all requirements }\end{array}$ & $\begin{array}{c}\text { No } \\
\text { (financial } \\
\text { constraints) }\end{array}$ & Yes & No (financial constraints) & No (limited funds) & $\begin{array}{l}\text { No (financial } \\
\text { constraints) }\end{array}$ & Yes \\
\hline Type of procurement & Centralized & Centralized & Centralized & Centralized & Centralized & Decentralized \\
\hline Method of procurement & Open tender & Restricted tender & $\begin{array}{c}\text { Sent by tertiary care } \\
\text { hospital }\end{array}$ & Purchased by wholesaler & $\begin{array}{c}\text { Sent by tertiary care } \\
\text { hospital }\end{array}$ & $\begin{array}{l}\text { Purchased by } \\
\text { wholesaler }\end{array}$ \\
\hline $\begin{array}{l}\text { Possession of } \\
\text { current EML }\end{array}$ & No & No & No & No & No & No \\
\hline Methods used & $\begin{array}{c}\text { Past } \\
\text { consumption }\end{array}$ & $\begin{array}{c}\text { Past } \\
\text { consumption, } \\
\text { morbidity }\end{array}$ & Past consumption & Past consumption & $\begin{array}{l}\text { Depend on } \\
\text { requirements }\end{array}$ & $\begin{array}{l}\text { Depend on } \\
\text { requirement }\end{array}$ \\
\hline $\begin{array}{l}\text { Problems with } \\
\text { quantification }\end{array}$ & $\begin{array}{l}\text { No, but limited } \\
\text { funds }\end{array}$ & No & $\begin{array}{l}\text { Insufficient funds } \\
\text { stock-outs }\end{array}$ & $\begin{array}{c}\text { Insufficient funds stock- } \\
\text { outs }\end{array}$ & $\begin{array}{l}\text { Limited funds } \\
\text { drugs stock-outs }\end{array}$ & No \\
\hline $\begin{array}{l}\text { Responsibility for contract } \\
\text { monitoring }\end{array}$ & $\begin{array}{l}\text { Procurement } \\
\text { Committee }\end{array}$ & Store pharmacist & Doctor & Doctor & None & Doctor \\
\hline
\end{tabular}

Table 1: Procurement and quantification of drugs in public and private primary, secondary and tertiary healthcare facilities in the two cities. 
Citation: Malik M, Hussain A, Shaffiq M, Hassali MAA, Shafie AA (2014) Role of Essential Drug List in Effective Management of Essential Anti-Malarial Drugs in Healthcare System of Pakistan Challenges in Policy Development to Practice. Pharmaceut Reg Affairs 3: 120. doi:10.4172/21677689.1000120

Page 4 of 7

\begin{tabular}{|c|c|c|c|c|c|c|c|}
\hline \multirow{2}{*}{\multicolumn{2}{|c|}{ Indicator }} & \multicolumn{2}{|c|}{ Tertiary } & \multicolumn{2}{|c|}{ Secondary } & \multicolumn{2}{|c|}{ Primary } \\
\hline & & Public & Private & Public & Private & Public & Private \\
\hline \multicolumn{8}{|c|}{ Distribution and Storage } \\
\hline \multicolumn{2}{|c|}{ Type of supply system } & Push system & $\begin{array}{l}\text { No specific } \\
\text { system }\end{array}$ & Push system & No specific system & Push system & No specific system \\
\hline \multicolumn{2}{|c|}{ Disposal of expired drugs } & $\begin{array}{l}\text { Returned to } \\
\text { supplier }\end{array}$ & $\begin{array}{l}\text { Returned to } \\
\text { supplier }\end{array}$ & Returned to supplier & Returned to supplier & $\begin{array}{l}\text { Returned to } \\
\text { supplier }\end{array}$ & Returned to supplier \\
\hline \multicolumn{2}{|c|}{ Appropriate storage of drugs } & No & Yes & No & No & No & No \\
\hline \multicolumn{8}{|c|}{ Inventory Control } \\
\hline \multicolumn{2}{|c|}{ Written procedures available } & Yes & No & No & No & No & No \\
\hline \multicolumn{2}{|c|}{ Type(s) of inventory records } & ledgers & Computers & ledgers & Ledgers & ledgers & ledgers \\
\hline \multicolumn{2}{|c|}{ Method of product circulation in store } & $\begin{array}{l}\text { FIFO } \\
\text { FEFO }\end{array}$ & FIFO & FIFO & FIFO & FIFO & FIFO \\
\hline \multicolumn{2}{|c|}{ Timing of stock taking } & Quarterly & Once a month & Quarterly & Quarterly & Quarterly & Quarterly \\
\hline \multicolumn{2}{|c|}{$\begin{array}{l}\text { Written information on store items } \\
\text { available }\end{array}$} & No & Monthly & No & Monthly & No & No \\
\hline \multicolumn{2}{|c|}{ Access to drug information resources } & $\begin{array}{l}\text { Yes: drug } \\
\text { formulary }\end{array}$ & $\begin{array}{l}\text { Yes: drug } \\
\text { formulary }\end{array}$ & No & No & No & No \\
\hline \multirow{4}{*}{$\begin{array}{l}\text { Computerized } \\
\text { system for }\end{array}$} & Tracking orders & No & No & No & No & No & No \\
\hline & Tracking delivery & No & No & No & No & No & No \\
\hline & Accounting/financial & No & No & No & No & No & No \\
\hline & Inventory control & No & No & No & No & No & No \\
\hline \multicolumn{8}{|c|}{ Human Resources } \\
\hline \multicolumn{2}{|c|}{ Adequate and appropriate staff } & No & Yes & No & No & No & No \\
\hline \multicolumn{2}{|c|}{ Major training needs } & $\begin{array}{l}\text { Inventory, } \\
\text { management, } \\
\text { computer } \\
\text { application }\end{array}$ & No & $\begin{array}{l}\text { Inventory, } \\
\text { management, } \\
\text { computer } \\
\text { application }\end{array}$ & No & $\begin{array}{l}\text { Inventory, } \\
\text { management } \\
\text { computer } \\
\text { application }\end{array}$ & No \\
\hline \multicolumn{2}{|c|}{$\begin{array}{l}\text { Key problems for human resource } \\
\text { development }\end{array}$} & $\begin{array}{l}\text { Proper } \\
\text { monitoring }\end{array}$ & None & Proper monitoring & Proper monitoring & Proper monitoring & Proper monitoring \\
\hline
\end{tabular}

Table 2: Drug supply and management in public and private primary, secondary and tertiary healthcare facilities.

\begin{tabular}{|c|c|c|c|c|c|c|c|c|}
\hline \multirow{3}{*}{ Anti-malarial Drugs } & \multicolumn{8}{|c|}{ Anti malarial drugs on hospital formulary of different healthcare facilities } \\
\hline & \multicolumn{2}{|c|}{ Primary $\mathbf{N}=\mathbf{2 0}$} & \multicolumn{2}{|c|}{ Secondary $N=10$} & \multicolumn{2}{|c|}{ Tertiary $\mathbf{N}=\mathbf{2 0}$} & \multicolumn{2}{|c|}{ Composite $\mathbf{N}=\mathbf{5 0}$} \\
\hline & $\begin{array}{l}\text { Public } n=10 \\
\quad F(\%)\end{array}$ & $\begin{array}{c}\text { Private } n=10 \\
F(\%)\end{array}$ & $\begin{array}{l}\text { Public } n=5 \\
\quad F(\%)\end{array}$ & $\begin{array}{c}\text { Private } n=5 \\
\quad F(\%)\end{array}$ & $\begin{array}{l}\text { Public } n=10 \\
\quad F(\%)\end{array}$ & $\begin{array}{c}\text { Private } n=10 \\
F(\%)\end{array}$ & $\begin{array}{l}\text { Public } n=25 \\
\quad F(\%)\end{array}$ & $\begin{array}{c}\text { Private } n=25 \\
F(\%)\end{array}$ \\
\hline $\begin{array}{l}\text { Chloroquine phosphate } 150 \\
\mathrm{mg} \text { (tab) }\end{array}$ & $10(100 \%)$ & $9(90 \%)$ & $5(100 \%)$ & $5(100 \%)$ & $10(100 \%)$ & $10(100 \%)$ & $25(100 \%)$ & $24(96 \%)$ \\
\hline $\begin{array}{l}\text { Chloroquine inj } 40 \text { mg/ml } 30 \\
\text { ml (vial) }\end{array}$ & $1(10 \%)$ & 0 & 0 & 0 & 0 & 0 & $1(4 \%)$ & 0 \\
\hline Chloroquine syrup $50 \mathrm{mg} / 5 \mathrm{ml}$ & $1(10 \%)$ & 0 & $1(20 \%)$ & 0 & $5(50 \%)$ & $4(40 \%)$ & $7(28 \%)$ & $4(16 \%)$ \\
\hline $\begin{array}{l}\text { Sulfadoxine/ pyrimethamine } \\
500 \mathrm{mg} / 25 \mathrm{mg} \text { (tab) }\end{array}$ & $4(40 \%)$ & $10(100 \%)$ & $2(40 \%)$ & $5(100 \%)$ & $5(50 \%)$ & $9(90 \%)$ & $11(44 \%)$ & $24(96 \%)$ \\
\hline Amodiaquine $200 \mathrm{mg}$ (tab) & $1(10 \%)$ & 0 & $1(20 \%)$ & 0 & $1(10 \%)$ & $2(20 \%)$ & $3(12 \%)$ & $2(8 \%)$ \\
\hline Quinine 300 mg (tab) & 0 & 0 & 0 & 0 & $1(10 \%)$ & $3(30 \%)$ & $1(4 \%)$ & $3(12 \%)$ \\
\hline Quinine 300 mg/ml (inj) & 0 & 0 & 0 & 0 & $1(10 \%)$ & $5(50 \%)$ & $1(4 \%)$ & $5(20 \%)$ \\
\hline $\begin{array}{l}\text { Artemether/ lumefantrine } 100 \\
\mathrm{mg} / 20 \mathrm{mg} \mathrm{tab}\end{array}$ & 0 & 0 & 0 & 0 & $2(20 \%)$ & $6(60 \%)$ & $2(8 \%)$ & $6(24 \%)$ \\
\hline $\begin{array}{l}\text { Artemether/ lumefantrine } 240 \\
\mathrm{mg} / 40 \mathrm{mg} \text { tab }\end{array}$ & 0 & $1(10 \%)$ & 0 & 0 & $3(30 \%)$ & $5(50 \%)$ & $3(12 \%)$ & $6(24 \%)$ \\
\hline $\begin{array}{l}\text { Artemether/ lumefantrine } 480 \\
\mathrm{mg} / 80 \mathrm{mg} \text { tab }\end{array}$ & 0 & $1(10 \%)$ & 0 & 0 & $2(20 \%)$ & $8(80 \%)$ & $2(8 \%)$ & $9(36 \%)$ \\
\hline
\end{tabular}

Table 3: Anti malarial drugs on hospital formulary of different public and private primary, secondary and tertiary healthcare facilities in the twin cities.

Availability of anti-malarial drugs in public and private primary, secondary and tertiary healthcare facilities

Chloroquine and sulfadoxine/pyrimethamine tablets were the most commonly available antimalarial drugs in most of the public and private primary, secondary and tertiary healthcare facilities. On the other hand chloroquine injections were not available in any of the public or private primary, secondary and tertiary healthcare facility. The availability of anti-malarial drugs was comparatively more in the private primary, secondary and tertiary healthcare facilities than the public healthcare facilities. A detail description of availability of antimalarial drugs in public and private primary, secondary and tertiary healthcare facilities in the twin cities is given in Table 4 .

Anti-malarial drug stock outs in public and private primary, secondary and tertiary healthcare facilities in the twin cities

The total average number of day's stock out of anti-malarial drugs in public primary healthcare facilities was 330.8 and 354.6 days in Islamabad and Rawalpindi cities, respectively. While on the other 
Citation: Malik M, Hussain A, Shaffiq M, Hassali MAA, Shafie AA (2014) Role of Essential Drug List in Effective Management of Essential Anti-Malarial Drugs in Healthcare System of Pakistan Challenges in Policy Development to Practice. Pharmaceut Reg Affairs 3: 120. doi:10.4172/21677689.1000120

Page 5 of 7

\begin{tabular}{|c|c|c|c|c|c|c|c|c|}
\hline \multirow{3}{*}{ Anti-malarial Drugs } & \multicolumn{8}{|c|}{ Availability of anti malarial drugs in different healthcare facilities } \\
\hline & \multicolumn{2}{|c|}{ Primary $\mathbf{N}=\mathbf{2 0}$} & \multicolumn{2}{|c|}{ Secondary $\mathrm{N}=10$} & \multicolumn{2}{|c|}{ Tertiary $\mathbf{N}=\mathbf{2 0}$} & \multicolumn{2}{|c|}{ Composite $\mathbf{N}=\mathbf{5 0}$} \\
\hline & $\begin{array}{c}\text { Public } n=10 \\
F(\%)\end{array}$ & $\begin{array}{c}\text { Private } n=10 \\
F(\%)\end{array}$ & $\begin{array}{c}\text { Public } n=5 \\
\quad F(\%)\end{array}$ & $\begin{array}{c}\text { Private } n=5 \\
F(\%)\end{array}$ & $\begin{array}{c}\text { Public } n=10 \\
F(\%)\end{array}$ & $\begin{array}{c}\text { Private } n=10 \\
F(\%)\end{array}$ & $\begin{array}{l}\text { Public } n=25 \\
\quad F(\%)\end{array}$ & $\begin{array}{c}\text { Private } n=25 \\
F(\%)\end{array}$ \\
\hline Chloroquine phosphate 150 mg (tab) & $3(30 \%)$ & $6(60 \%)$ & $0(0 \%)$ & $5(100 \%)$ & $7(70 \%)$ & $9(90 \%)$ & $10(40 \%)$ & $20(80 \%)$ \\
\hline Chloroquine inj 40 mg/ml 30 ml (vial) & $0(0 \%)$ & $0(0 \%)$ & $0(0 \%)$ & $0(0 \%)$ & $0(0 \%)$ & $0(0 \%)$ & $0(0 \%)$ & $0(0 \%)$ \\
\hline Chloroquine syrup $50 \mathrm{mg} / 5 \mathrm{ml}$ & $0(0 \%)$ & $0(0 \%)$ & $0(0 \%)$ & $0(0 \%)$ & $4(40 \%)$ & $4(40 \%)$ & $4(16 \%)$ & $4(16 \%)$ \\
\hline $\begin{array}{l}\text { Sulfadoxine/ pyrimethamine } 500 \mathrm{mg} / 25 \\
\mathrm{mg} \text { (tab) }\end{array}$ & $0(0 \%)$ & $9(90 \%)$ & $0(0 \%)$ & $4(80 \%)$ & $4(40 \%)$ & $8(80 \%)$ & $4(16 \%)$ & $21(84 \%)$ \\
\hline Amodiaquine 200 mg (tab) & $0(0 \%)$ & $0(0 \%)$ & $1(20 \%)$ & $0(0 \%)$ & $1(10 \%)$ & $1(10 \%)$ & $2(8 \%)$ & $1(4 \%)$ \\
\hline Quinine 300 mg (tab) & $0(0 \%)$ & $0(0 \%)$ & $0(0 \%)$ & $0(0 \%)$ & $1(10 \%)$ & $3(30 \%)$ & $1(4 \%)$ & $3(12 \%)$ \\
\hline Quinine 300 mg/ml (inj) & $0(0 \%)$ & $0(0 \%)$ & $0(0 \%)$ & $0(0 \%)$ & $1(10 \%)$ & $3(30 \%)$ & $1(4 \%)$ & $3(12 \%)$ \\
\hline $\begin{array}{l}\text { Artemether/ lumefantrine } 100 \mathrm{mg} / 20 \mathrm{mg} \\
\text { tab }\end{array}$ & $0(0 \%)$ & $0(0 \%)$ & $0(0 \%)$ & $0(0 \%)$ & $2(20 \%)$ & $5(50 \%)$ & $2(8 \%)$ & $5(20 \%)$ \\
\hline $\begin{array}{l}\text { Artemether/ lumefantrine } 240 \mathrm{mg} / 40 \mathrm{mg} \\
\text { tab }\end{array}$ & $0(0 \%)$ & $2(20 \%)$ & $0(0 \%)$ & $0(0 \%)$ & $2(20 \%)$ & $5(50 \%)$ & $2(8 \%)$ & $7(28 \%)$ \\
\hline $\begin{array}{l}\text { Artemether/ lumefantrine } 480 \mathrm{mg} / 80 \mathrm{mg} \\
\text { tab }\end{array}$ & $0(0 \%)$ & $1(10 \%)$ & $0(0 \%)$ & $0(0 \%)$ & $0(0 \%)$ & $7(70 \%)$ & $0(0 \%)$ & $8(32 \%)$ \\
\hline
\end{tabular}

Table 4: Availability of anti malarial drugs in public and private primary, secondary and tertiary healthcare facilities

hand, total average number of day's stock out of anti-malarial drugs in private primary healthcare facilities was 292 and 308.9 days in Islamabad and Rawalpindi respectively. Stock outs of anti-malarial drugs were observed comparatively more in public primary healthcare facilities than in private healthcare facilities. A detail description of number of day's stock out of antimalarial drugs in public and private primary healthcare facilities in the twin cities is given in Table 5.

\section{Anti-malarial drug stock outs in public and private secondary healthcare facilities in the twin cities}

The total average number of day's stock out of anti-malarial drugs in public secondary healthcare facilities was 336.9 while on the other hand total average number of day's stock out of anti-malarial drugs in private tertiary healthcare facilities was 297.4 in Rawalpindi. Stock outs of anti-malarial drugs were observed comparatively more in public secondary healthcare facilities than in private healthcare facilities. A detail description of number of day's stock out of anti-malarial drugs in public and private secondary healthcare facilities in the twin cities is given in Table 6.

\section{Anti-malarial drug stock outs in public and private tertiary healthcare facilities in the twin cities}

The total average number of day's stock out of anti-malarial drugs in public tertiary healthcare facilities was 230.3 and 291.9 days in Islamabad and Rawalpindi cities, respectively. While on the other hand total average number of day's stock out of anti-malarial drugs in private tertiary healthcare facilities was 170.2 and 210.4 days in Islamabad and Rawalpindi respectively. Stock outs of anti-malarial drugs were observed comparatively more in public tertiary healthcare facilities than in private healthcare facilities. A detail description of number of day's stock out of anti-malarial drugs in public and private tertiary healthcare facilities in the twin cities is given in Table 7.

\section{Discussion}

The pharmaceutical sector of Pakistan, with a global market value share of over 1.8 billion US dollars, is particularly susceptible to inappropriate drug management and procurement. Drug management involves appropriate drug selection; procurement, quantification, inventory management, aggregate purchasing, public bidding contests, proper allocation of resources, storage, supply, record keeping and quality control checks. These processes are often poorly monitored, and hence can lead to major drugs stock out and results in low quality services [9]. The results of the present study highlighted different process involved in drug management in public and private tertiary, secondary and primary healthcare facilities. The DTC was in place in all the public and private tertiary healthcare facilities and doctors were in charge of the committees. The public tertiary hospitals were responsible for procurement of drugs for their respective secondary and primary healthcare facilities. A pharmacist was available in public tertiary and secondary healthcare facilities and was part of procurement committee but did not play an active role in drug selection and procurement. This might be due to the reluctance from doctors in accepting the clinical role of hospital pharmacists in Pakistan. Similar situation has been reported from other developing countries including Bangladesh $[10,11]$.

On the other hand pharmacist was not available in both public and private primary healthcare facilities. This might be linked to non affordability of the healthcare facilities to hire pharmacists due to limited resources. The type of procurement being performed was centralized and through open and restricted tenders in the public and private tertiary healthcare facilities respectively. Some drugs, despite being on the essential drugs list, were not available in any of the public or private tertiary, secondary or primary healthcare facility because they had not been part of procurement list by the facilities. The main reason for this might be the unavailability of essential drugs list in all the healthcare facilities and procurement of drugs being performed through hospital formulary. Drugs were being quantified on the basis of their past consumption. Ledgers were used for record keeping in public and private tertiary, secondary and primary healthcare facilities while computers were being used in few of the private tertiary, secondary and primary healthcare facilities. Major drug management challenges included inadequate funding, storage facilities, inadequate monitoring, need for training in inventory management, drug management and computer applications in all the public tertiary, secondary and primary healthcare facilities. The results of the present study are in line with another study which showed similar drug management systems in different healthcare facilities in Nigeria [7].

An efficient pharmaceutical management system ensures a constant supply of appropriate quantities of drugs in the healthcare facility. The results of the present study showed that key anti-malarial drugs were not always in stock in healthcare facilities. An interesting finding was observed that artemether/lumefentrine being the recommended drug in the national standard treatment guidelines for the treatment of malaria caused by Plasmodium. Falciparum was not not included in 
Citation: Malik M, Hussain A, Shaffiq M, Hassali MAA, Shafie AA (2014) Role of Essential Drug List in Effective Management of Essential Anti-Malarial Drugs in Healthcare System of Pakistan Challenges in Policy Development to Practice. Pharmaceut Reg Affairs 3: 120. doi:10.4172/21677689.1000120

Page 6 of 7

\begin{tabular}{|c|c|c|c|c|}
\hline \multirow{3}{*}{ Name of drugs } & \multicolumn{4}{|c|}{ Number of days stock out of anti-malarial drugs at primary healthcare facilities } \\
\hline & \multicolumn{2}{|c|}{ Islamabad } & \multicolumn{2}{|c|}{ Rawalpindi } \\
\hline & Public Mean ( \pm S.D) & Private Mean ( \pm S.D) & Public Mean ( \pm S.D) & Private Mean ( \pm S.D) \\
\hline Chloroquine phosphate 150 mg (tab) & $176( \pm 175.45)$ & $0( \pm 0.00)$ & $261( \pm 160.60)$ & $145( \pm 152.39)$ \\
\hline Chloroquine injection 40 mg/ml $30 \mathrm{ml}$ (vial) & $304( \pm 136.40)$ & $365( \pm 0.00)$ & $365( \pm 0.00)$ & $365( \pm 0.00)$ \\
\hline Chloroquine syrup 50 mg/5 ml & $298( \pm 149.8)$ & $365( \pm 0.00)$ & $365( \pm 0.00)$ & $365( \pm 0.00)$ \\
\hline Sulfadoxine/pyrimethamine 500 mg/25 mg (tab) & $365( \pm 0.00)$ & $0( \pm 0)$ & $365( \pm 0.00)$ & $24( \pm 39.11)$ \\
\hline Amodiaquine 200 mg (tab) & $340( \pm 55.90)$ & $365( \pm 0.00)$ & $365( \pm 0.00)$ & $365( \pm 0.00)$ \\
\hline Quinine 300 mg (tab) & $365( \pm 0.00)$ & $365( \pm 0.00)$ & $365( \pm 0.00)$ & $365( \pm 0.00)$ \\
\hline Quinine 300 mg/ml (inj) & $365( \pm 0.00)$ & $365( \pm 0.00)$ & $365( \pm 0.00)$ & $365( \pm 0.00)$ \\
\hline Artemether/lumefantrine $100 \mathrm{mg} / 20 \mathrm{mg} \mathrm{(tab)}$ & $365( \pm 0.00)$ & $365( \pm 0.00)$ & $365( \pm 0.00)$ & $365( \pm 0.00)$ \\
\hline Artemether/lumefantrine 240 mg/40 mg (tab) & $365( \pm 0.00)$ & $365( \pm 0.00)$ & $365( \pm 0.00)$ & $365( \pm 0.00)$ \\
\hline Artemether/lumefantrine 480 mg/80 mg (tab) & $365( \pm 0.00)$ & $365( \pm 0.00)$ & $365( \pm 0.00)$ & $365( \pm 0.00)$ \\
\hline Total Average days stock-out & 330.8 & 292 & 354.6 & 308.9 \\
\hline
\end{tabular}

Table 5: Anti-malarial drugs stock outs in public and private primary healthcare facilities in the twin cities.

\begin{tabular}{|c|c|c|}
\hline \multirow{3}{*}{ Name of drugs } & \multicolumn{2}{|c|}{ Number of days stock out of anti-malarial drugs at secondary healthcare facilities } \\
\hline & \multicolumn{2}{|c|}{ Rawalpindi } \\
\hline & Public Mean ( \pm S.D) & Private Mean ( \pm S.D) \\
\hline Chloroquine phosphate 150 mg (tab) & $304( \pm 136.40)$ & $12( \pm 26.83)$ \\
\hline Chloroquine inj 40 mg/ml $30 \mathrm{ml}$ (vial) & $298( \pm 149.81)$ & $365( \pm 0.00)$ \\
\hline Chloroquine syrup $50 \mathrm{mg} / 5 \mathrm{ml}$ & $212( \pm 146.48)$ & $365( \pm 0.00)$ \\
\hline Sulfadoxine/pyrimethamine $500 \mathrm{mg} / 25 \mathrm{mg}$ tab & $365( \pm 0.00)$ & $42( \pm 65.75)$ \\
\hline Amodiaquine $200 \mathrm{mg}$ (tab) & $365( \pm 0.00)$ & $365( \pm 0.00)$ \\
\hline Quinine 300 mg (tab) & $365( \pm 0.00)$ & $365( \pm 0.00)$ \\
\hline Quinine 300 mg/ml (inj) & $365( \pm 0.00)$ & $365( \pm 0.00)$ \\
\hline Artemether/lumefantrine 100 mg/20 mg (tab) & $365( \pm 0.00)$ & $365( \pm 0.00)$ \\
\hline Artemether/lumefantrine 240 mg/40 mg (tab) & $365( \pm 0.00)$ & $365( \pm 0.00)$ \\
\hline Artemether/lumefantrine $\mathbf{4 8 0} \mathbf{~ m g} / \mathbf{8 0} \mathbf{~ m g ~ ( t a b )}$ & $365( \pm 0.00)$ & $365( \pm 0.00)$ \\
\hline Total Average days stock-out & 336.9 & 297.4 \\
\hline
\end{tabular}

Table 6: Anti-malarial drugs stock outs in public and private secondary healthcare facilities in the twin cities.

\begin{tabular}{|c|c|c|c|c|}
\hline \multirow{3}{*}{ Name of drugs } & \multicolumn{4}{|c|}{ Number of days stock out of anti-malarial drugs at tertiary healthcare facilities } \\
\hline & \multicolumn{2}{|c|}{ Islamabad } & \multicolumn{2}{|c|}{ Rawalpindi } \\
\hline & Public Mean ( \pm S.D) & Private Mean ( \pm S.D) & Public Mean ( \pm S.D) & Private Mean ( \pm S.D) \\
\hline Chloroquine phosphate 150 mg (tab) & $12( \pm 26.83)$ & $0( \pm 0)$ & $176( \pm 183.07)$ & $73( \pm 163.23)$ \\
\hline Chloroquine injection $40 \mathrm{mg} / \mathrm{ml} 30 \mathrm{ml}$ (vial) & $292( \pm 163.23)$ & $365( \pm 0.00)$ & $365( \pm 0.00)$ & $365( \pm 0.00)$ \\
\hline Chloroquine syrup $50 \mathrm{mg} / 5 \mathrm{ml}$ & $150( \pm 196.43)$ & $164( \pm 184.70)$ & $292( \pm 163.23)$ & $292( \pm 163.23)$ \\
\hline Sulfadoxine/pyrimethamine $500 \mathrm{mg} / 25 \mathrm{mg}$ (tab) & $158( \pm 190.54)$ & $42( \pm 65.75)$ & $170( \pm 184.62)$ & $73( \pm 163.23)$ \\
\hline Amodiaquine 200 mg (tab) & $225( \pm 191.99)$ & $219( \pm 199.99)$ & $365( \pm 0.00)$ & $365( \pm 0.00)$ \\
\hline Quinine 300 mg (tab) & $219( \pm 199.99)$ & $219( \pm 199.99)$ & $365( \pm 0.00)$ & $237( \pm 178.13)$ \\
\hline Quinine 300 mg/ml (inj) & $219( \pm 199.99)$ & $255( \pm 163.51)$ & $365( \pm 0.00)$ & $243( \pm 168.39)$ \\
\hline Artemether/lumefantrine $100 \mathrm{mg} / 20 \mathrm{mg}$ (tab) & $146( \pm 199.99)$ & $73( \pm 163.72)$ & $365( \pm 0.00)$ & $292( \pm 163.23)$ \\
\hline Artemether/lumefantrine $240 \mathrm{mg} / 40 \mathrm{mg}$ (tab) & $219( \pm 199.99)$ & $219( \pm 199.99)$ & $219( \pm 199.91)$ & $146( \pm 199.99)$ \\
\hline Artemether/lumefantrine $480 \mathrm{mg} / 80 \mathrm{mg}$ (tab) & $292( \pm 163.23)$ & $146( \pm 199.99)$ & $219( \pm 199.91)$ & $12( \pm 26.83)$ \\
\hline Total Average days stock-out & 193.2 & 170.2 & 290.1 & 209.8 \\
\hline
\end{tabular}

Table 7: Anti-malarial drugs stock outs in public and tertiary healthcare facilities in the twin cities.

the essential drug list of Pakistan. This reflects negligence on the part of stakeholders while updating the essential drug list. Chloroquine and sulphadoxine/ pyremethamine were the most commonly available anti-malarial drugs at both the public and private healthcare facilities. Major stock outs of anti-malarial drugs were seen in both public and private primary, secondary and tertiary healthcare facilities, but relatively more frequent in the public sector. Most of the prescribed anti-malarial drugs in the study were not actually dispensed due to their unavailability in the healthcare facilities and were bought from the community pharmacies located near the healthcare facilities. This might be due to inadequate funds for purchasing of drugs and lack of implementation of essential drugs list in the healthcare facilities at all levels. Similar results of unavailability of key anti-malarial drugs in healthcare facilities at different levels were reported by several studies and highlighted the need for ensuring the availability of essential antimalarial drugs on a regular basis for the promotion of rational drug use $[5,12,13]$.

\section{Conclusion}

The results of the present study showed that drug management follows different methods in both public and private primary, secondary and tertiary healthcare facilities in the two cities. Essential drug list was not available in any of the healthcare facility. Although, major stock outs of anti-malarial drugs were seen in both public and private healthcare facilities but somehow the situation was more prevalent in the public sector. A pharmacist was available in public tertiary and secondary healthcare facilities and was part of procurement committee 
but did not play an active role in drug selection and procurement. This highlights gaps in the overall drug management system including poor coordination of procurement and distribution, inappropriate inventory management, financial constraints to purchase all the essential anti-malarial drugs and lack of implementation of essential drugs list for procurement of drugs at all levels. Furthermore, it was surprising to notice that the essential drug list of Pakistan lacks few drugs recommended in the national standard treatment guidelines for malaria. This reflects negligence on the part of stakeholders while updating the essential drug list. Innovative approaches are needed to allocate funds for the public sector through collaborative working with the private sector, implementation of national essential medicine list in all the healthcare facilities and promotion of generic prescribing. This will not only improve the overall drug management in the healthcare facilities at all levels but will also ensure the availability of drugs and reduce cost of healthcare system.

\section{Acknowledgements}

The authors acknowledge Malaria Control Program and MS of respective hospitals for their support during the data collection.

\section{Key Messages}

- Major drug stock-outs of essential anti-malarial drugs in all the healthcare facilities

- Lack of implementation of Essential drug list

- Negligence on part of stakeholders in updating the list in accordance with the national standard treatment guidelines for malaria

- Inadequate role of pharmacist in drug selection and procurement due to reluctance from the prescribers.

- Financial constraints to ensure uninterrupted availability of drugs.

\section{References}

1. Quick JD, Hogerzeil HV, Velasquez G, Rago L (2002) Twenty-five years of essential medicines. Bull World Health Organ 80: 913-914.

2. Mccabe A (2009) Private Sector Pharmaceutical Supply and Distribution Chains: Ghana, Mali and Malawi. World Health Organization.

3. Karande S, Sankhe P, Kulkarni M (2005) Patterns of prescription and drug dispensing. Indian J Pediatr 72: 117-121.

4. Bloland PB, Kachur SP, Williams HA (2003) Trends in antimalarial drug deployment in sub-Saharan Africa. J Exp Biol 206: 3761-3769.

5. Mannan AA, Malik EM, Ali KM (2009) Anti-malarial prescribing and dispensing practices in health centres of Khartoum state, 2003-04. East Mediterr Health J 15: 123-8.

6. Cameron A, Ewen M, Degnan RD, Ball D, Laing R (2009) Medicine prices availability, and affordability in 36 developing and middle-income countries: a secondary analysis. Lancet 373: 240-249.

7. Tetteh G, Adeya G (2005) Rapid Assessment of Antimalarial Drug Availability and Use in Nigeria, February-March 2004. Management Sciences for health.

8. Ministry of Health (2007) National Essential Medicines List of Pakistan Government of Pakistan.

9. World Health Organization (2008) Health System Governance.

10. Shaikh S (2009) Development of hospital pharmacy in Bangladesh. PJ online.

11. Azhar S, Hassali MA, Ibrahim M, Ahmad M, Masood I, et al. (2009) The role of pharmacists in developing countries: the current scenario in Pakistan. Hum Resour Health 7: 54.

12. Guyon AB, Barman A, Ahmed J, Ahmed A, Alam M (1994) A baseline survey on use of drugs at the primary health care level in Bangladesh. Bull World Health Organ 72: 265-271.

13. Ahmed SM, Islam QS (2012) Availability and rational use of drugs in primary healthcare facilities following the national drug policy of 1982: is Bangladesh on right track? J Health Popul Nutr 30: 99-108. 